\title{
INDUSTRY 4.0 IMPACTS ON THE DEVELOPMENT OF RETAIL E-COMMERCE.
}

\author{
Nogueira, Edithe Oliveira \\ Student in Production and Systems Engineering \\ Universidade do Vale do Rio dos Sinos - UNISINOS. \\ São Leopoldo-RS BRAZIL. \\ (edithe_nogueira@hotmail.com) \\ Borchardt, Miriam \\ $\mathrm{PhD}$ in Production Engineering. Engineering \\ Universidade do Vale do Rio dos Sinos - UNISINOS. \\ São Leopoldo-RS BRAZIL. \\ (miriamb@unisinos.br)
}

DOI: 10.31364/SCIRJ/V9.i09.2021.P0921876

http://dx.doi.org/10.31364/SCIRJ/v9.i09.2021.P0921876

\begin{abstract}
Technological developments that have taken place mainly since the turn of the millennium and the convergence of applications in the technological, physical and biological areas have been some of the main factors for what is being called Industry 4.0. This industry revolution is based on principles such as interoperability, virtualization, decentralization, service orientation and, consequently, impacts on e-commerce operations, presenting several advantages in business strategy. However, it is necessary to understand which technologies should be implemented in the production process, bringing more efficiency and productivity, maximizing the use of technology, and what it can offer. Thus, the objective of this research is to identify and explore the effects and impacts of industry 4.0 on retail e-commerce. The research carried out has a qualitative approach and is of the exploratory type, whose data collection technique was the bibliographical research, looking for articles in the CAPES Database. The search results did not return articles that dealt with the themes together, thus, aspects of industry 4.0 and ecommerce were identified by different authors to then carry out some analyzes and discussions.
\end{abstract}

key words: Industry 4.0. E-commerce. Internet of Things (IoT).

\section{INTRODUCTION}

Production management under the concept of Industry 4.0 linked to e-commerce changes the way production is planned, which no longer depends on scale, but on the needs of the customer, who becomes the center of decision, i.e. the customer's requirements define the production schedule. Thus, the customer can customize his product and the company will deliver it according to the specific demand. E-commerce is then an ally to reduce costs in the industry, such as inventories, among other production costs (ZHAO; FENG, 2017).
It is worth noting that the Fourth Industrial Revolution is not limited to industrial production, but manifests itself in all

aspects of society, including technology, production, consumption, and is influencing all fields of human life (SCHWAB, 2016). There is still no clear understanding about this technological trend, and it is worth clarifying about some of the basic concepts related to the Fourth Industrial Revolution or Industry 4.0 and its relations with e-commerce, as well as on which aspects these topics have been researched. Thus, this article aims to identify and explore the impacts and effects of Industry 4.0 on retail e-commerce, providing a brief overview of recent research on the subject. To achieve this goal, a qualitative and exploratory research was conducted. Data was collected through a bibliographic search of books and scientific articles indexed in Google Scholar and in the CAPES database. Documentary research sources were also consulted, such as online articles or websites that dealt with the themes addressed in the study, as well as research reports on the subject.

Therefore, the Strategic Initiative Industry 4.0 offers great opportunities for the development of emerging industries in several countries, such as high technology. So, understanding more about this model can help achieve development goals for Brazil (FERREIRA, 2017).

\section{THEORETICAL BACKGROUND}

\subsection{INDUSTRY 4.0}

Nowadays, it has been mentioned that the world is at the peak of what is referred to as the Fourth Industrial Revolution, which began at the turn of the 21 st century and is distinguished from the first three industrial revolutions due to the changes that have been occurring in various aspects such as: computing 
power, connectivity, robotics, internet of things (IoT) , artificial intelligence (AI), 3D printing, autonomous vehicles, biotechnology, nanotechnology, materials science, and quantum computing (SCHWAB, 2016). Such technological innovations are considerably changing the way products are manufactured and business transactions have been done in real time (GILCHRIST, 2016; SCHWAB, 2016).

The Fourth Industrial Revolution is based on the integration of network and intelligence systems. In 2011 at the Hanover trade fair, the German government presented the concept of "Industry 4.0" - an association of representatives from business, politics, and academia - which focused on an approach to strengthening the competitiveness of German manufacturing industry. In 2013, recommendations for implementing "Strategic Initiative Industry 4.0" (Strategic Initiative Industry 4.0). This action represented major impacts for the entire world and initiated what has been widely referred to as the Fourth Industrial Revolution or Industry 4.0 (HERMANN; PENTEK; OTTO, 2015).

Furthermore, the fusion of different types of technologies is blurring the dividing lines between physical, digital, and biological areas, based on the use of cyber-physical systems and the digitalization of production systems (SCHWAB, 2016). Such changes threaten to generate more unemployment, particularly among unskilled workers in developed and developing countries. For Schwab (2016, p. 4) "The fundamental and global nature of this revolution means that it will affect and be influenced by all countries, economies, sectors, and people." The author adds that, due to the wide application of artificial intelligence and robotics, this revolution may threaten the current economic order and bring about a new world economic order.

The following figure schematically shows some characteristics of each of the industrial revolutions considering the degree of complexity of the transformations and the historical period in which they occurred.

Figure 1 - The four industrial revolutions

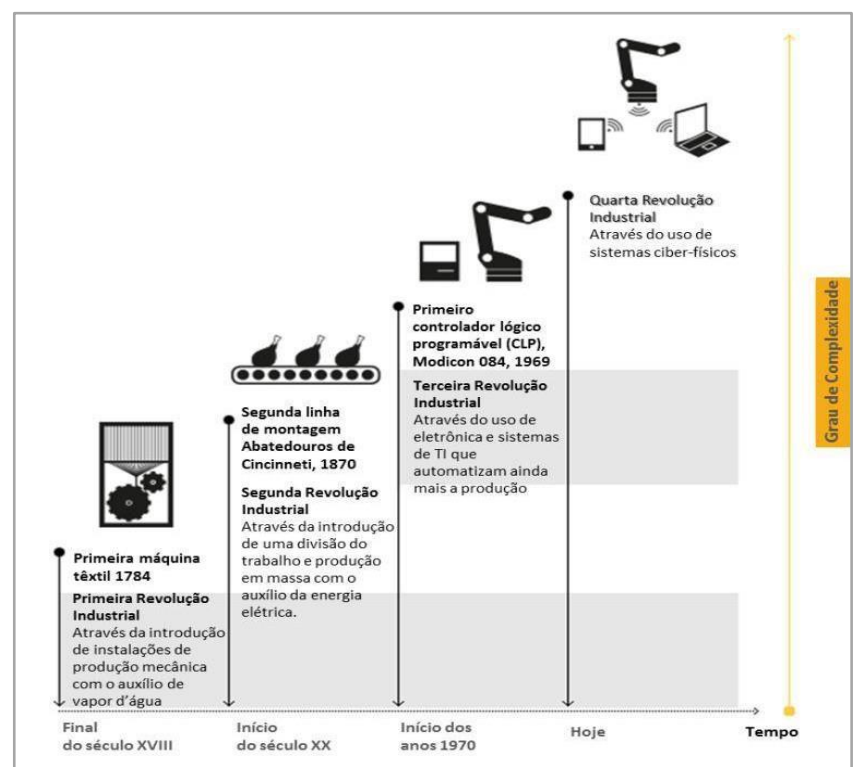

Source: reprinted from Ferreira (2017)

From an evolutionary point of view, to date there have been three major advances in technology that have triggered major economic, cultural, and social transformations around the world. The First Industrial Revolution, which began in England and took place between 1760 and 1840, introduced steam and hydraulic machines in factories, in addition to the construction of railroads that shortened distances and transport time. The Second Industrial Revolution, which occurred at the end of the 19th century, with the introduction of electricity, brought transformative changes to the factories of the time, creating assembly lines, the separation of components and the manufacture of products based on the division of labor. This modification in the industries started mass production and made products more accessible to people, creating the consumer society. The Third Industrial Revolution, which occurred as of the 1970s, also known as the Digital Revolution, which allowed the wide application of electronic and information technologies introducing automation to the production process (FERREIRA, 2017).

In the United States this industrial revolution has also been referred to as the "Industrial Internet", a term for "Industrial Internet of Things". This concept was presented by the company General Electric (GE), based on enabling technologies that create the integration of virtuality and reality, that is, a network where clever objects communicate with each other, which is supported by the internet of things (GILCHRIST, 2016).

According to Schwab (2016), developments in digital, physical, and biological technologies are the three key technological drivers of the Fourth Industrial Revolution, which was basically driven by new and lasting advances in these three areas, as well as a major merger between them. The key technological drivers in each area are summarized in the chart 1. 
Chart 1 - Technological Impetus for the Fourth Industrial Revolution

\begin{tabular}{ll}
\hline Categories & \multicolumn{1}{c}{ Manifestations } \\
\hline Digital & $\begin{array}{l}\text { Internet of Things (IoT) } \\
\text { Artificial Intelligence (AI) } \\
\text { Machine arning (machine learning) } \\
\text { Big data and cloud computing }\end{array}$ \\
\hline Physics & $\begin{array}{l}\text { Autonomous Cars } \\
\text { 3D Printing } \\
\text { Advanced Robotics } \\
\text { New Materials }\end{array}$ \\
\hline Biologic & $\begin{array}{l}\text { Genetic Engineering } \\
\text { Synthetic Biology } \\
\text { Neurotechnology }\end{array}$ \\
\hline
\end{tabular}

Source: prepared by the author based on Schwab (2016).

However, these transformations are not limited to industrial production alone, but manifest themselves in all aspects of society, including technology, production, consumption, and have influenced all fields of human life. While the greatest technological advances of the previous industrial revolutions originated in the areas of hardware or machinery, the technological drivers for the Fourth Industrial Revolution originated mainly in the area of software, as detailed below.

\subsection{Technological Drivers for the Fourth Industrial Revolution}

\subsubsection{Digital}

Digital technology is the fundamental driving force for the Fourth Industrial Revolution, as virtually all of the innovations and advances introduced in the Fourth Industrial Revolution only became possible and were enhanced due to digital power (SCHWAB, 2016). Digital technologies are making the whole world digitally connected and are manifested mainly in four aspects: internet of things, artificial intelligence, machine learning, big data, cloud computing, all connected through digital platforms.

The basic idea of the internet of things is to make things generally present in our daily lives, such as household appliances and electronic and digital devices in general, communicate with each other to achieve common goals. IoT technology can identify, locate, track, as well as monitor subjects; and can even trigger events autonomously and in real time (GILCHRIST, 2016).

Schwab (2016) predicts that we will have smart sensors to monitor everything connected to the internet which will provide insight into the environment in an integral way. IoT products have been playing an increasingly important role in smart homes, traffic logistics, environmental protection, public safety, intelligent fire control, industrial monitoring, personal health, and other areas.
However, it is important to differentiate vertical IoT strategies [...] such as consumer, commercial, and industrial forms of the Internet from the broader horizontal concept of the Internet of Things (IoT), as they have very different target audiences, technical requirements, and strategies. For example, the consumer market has the highest visibility in the market with smart homes, personal connectivity through physical activity (fitness) monitors, integrated entertainment devices, and personal car monitors. Similarly, the commercial market has high marketability as they have services that span financial and investment products such as banking, insurance, financial services, and ecommerce that focus on consumer history, performance, and value. Enterprise IoT, on the other hand, is a vertical that includes small, medium, and large enterprises (GILCHRIST, 2016, p. 1).

Another technology that had a lot of development was artificial intelligence (AI), which basically applies computing to simulate the thought process and behavior of human beings (such as reasoning and planning). Currently, AI has been widely employed by companies such as Facebook and Google, among others, by storing data and information to assist in complex decisions through algorithms (SCHWAB, 2016).

Machine learning is one of the most active developments in AI and provides computer systems with the ability to find hidden information without having been previously programmed for such a function. Basically, algorithms can iteratively learn from existing data, meaning that with machine learning computers can adapt and make reliable and repeatable decisions when exposed to new data. Its application ranges from text-based sentiment analysis, biometric identification, security market analysis and image recognition, etc. (SCHWAB, 2016).

With the development of sensors, improved storage capacity, and the progress of machine learning, the volume of data has increased dramatically, introducing the concept of big data. In short, a large amount of data is generated from a variety of features capturing online operations (e-commerce transactions, web browsing, social media interactions, etc.). These online interactions contain a large volume of data and the concept of big data means working on this large flow of data with respect 
to its analysis, capture, search, sharing, storage, transfer, visualization, and data privacy information (SCHWAB, 2016). Complementarily, with the emergence of cloud computing, it was possible to implement improvements in the treatment of big data, allowing the leasing of IT resources, whether they are infrastructure, platform or software applications, to offer services in the form of a subscription, decoupling the need for large equipment acquisition and virtualizing data storage options (SCHWAB, 2016).

\subsubsection{Physics}

Physical technologies make achievements visible and are probably the most well-known influencers for the Fourth Industrial Revolution, as they impact daily life most directly, mainly due to the most widespread physical manifestations: $3 \mathrm{D}$ printing, autonomous vehicles, advanced robotics, and new materials (SCHWAB, 2016).

$3 \mathrm{D}$ printing is a technology that enables the fabrication of a three-dimensional physical object by printing layer upon layer from a 3D digital design or model, while subtractive manufacturing technology (currently the most widely used) produces the desired shape by removing layer upon layer of a block of material. Thus, 3D printing is additive, that is, the object is created in three dimensions from a digital model. 3D technology encourages innovation because of the unprecedented freedom of design. There is no need for specific machines for manufacturing, which avoids extra costs and manufacturing lead times. For now, these applications have been most widely employed by the automotive, aerospace, and medical industries. However, they are expanding into areas such as the arts, sculpture, design, and architecture. As the main social and economic influences of 3D printing are customization, affordability, and decentralization with the creation of infofactories (SCHWAB, 2016).

The invention of autonomous vehicles allows cars to operate without the need of a driver. Such vehicles have advanced sensors, active steering, GPS navigation, lasers, and radar, and have the potential to substantially change transportation systems by preventing deadly failures, provide mobility for the elderly and disabled, increase road capacity, with fuel savings and reduced pollutant emissions. In addition, autonomous vehicles, as one of the most innovative fields of industrial production, will create a new expansion to economic growth (SCHWAB, 2016).

1) Further robotics will make it possible to overcome rigid tasks and improve interaction between robots and between robots and humans, due to the advancement of sensors that empower robots in better understanding their environment to perform varied tasks. The new materials are lighter, stronger, recyclable, and adaptable, most notably nano materials such as graphene, which is 200 times stronger than steel, millions of times thinner than a human hair, and an efficient conductor of heat and electricity. (SCHWAB, 2016).

\subsubsection{Biological}

The major advances in biotechnological development driving the Fourth Industrial Revolution focus on genetic technology, synthetic biology and neurotechnologies. Genetic study has always been one of the vital branches for biological research. With advances in computing power there has been considerable progress in reducing cost, increasing ease and efficiency in sequencing, activation and gene editing. It took over ten years to complete the Human Genome Project and at a skyrocketing cost, but today, a genome can be sequenced in a few hours for less than a thousand dollars (SCHWAB, 2016). In addition, progress in genetic engineering helps people obtain higher agricultural yields by increasing the robustness, efficiency and productivity of crop breeding. Genetic engineering makes it possible to interfere with and modify living things (animals, plants) and adapt them to adverse conditions. With synthetic biology it is possible to modify existing organisms by altering their genetic codes, making it possible to create personalized organisms or recreate organs, but these technological advances raise ethical issues that need further debate and regulation (SCHWAB, 2016).

Neurotechnology makes it possible to monitor brain activity and observe how the brain changes and interacts with the outside world. Due to the efforts of research institutions and the combination of information and artificial intelligence technology, the applications of brain science have gradually increased, with the development of neuroimaging and neurostimulation devices that although in the early stages can improve aspects such as communication, intelligence, cognitive ability, and in treatments against diseases or even military applications. An example of the advancement of these technologies is in the application of neurotechnology to help paralyzed people control prosthetic limbs or wheelchairs with their thoughts (SCHWAB, 2016).

It is also possible to monitor brain activity in real time, which offers numerous opportunities to help fight addictions, regulate eating behavior, and improve performance in sports or studies. From a medical treatment point of view, the ability to collect, process, store, and compare large amounts of data related to brain activity makes it possible to improve the diagnosis and efficiency of the treatment of brain disorders and mental health-related problems. IBM's Watson supercomputer system, for example, can make personalized treatment plans for cancer patients by comparing data from previous patients, treatments, and genetic information with updated medical knowledge in just a few minutes. In addition, the next generation of computers, designed in conjunction with the application of brain science, is expected to be able to reason, predict and react like the human cortex (SCHWAB, 2016).

\subsection{E-commerce for Industry 4.0}

Electronic commerce (e-commerce) has been increasingly used by companies as a sales channel, but also as a process management tool for commercial and production activities, due to the facilities it provides for interconnection with the areas of production and logistics. The so-called ebusiness employs the technology infrastructure and applications to optimize existing and new business processes (UZOKA, SELEKA, 2006)

$\mathrm{B} 2 \mathrm{~B}, \mathrm{~B} 2 \mathrm{C}, \mathrm{C} 2 \mathrm{C}, \mathrm{C} 2 \mathrm{~B}, \mathrm{O} 2 \mathrm{O}$ are the five major e-commerce business models. B2B mainly refers to business transactions from companies to companies via the Internet. The traditional business model that consists of purchasing, sales, and other business processes are part of the B2B model. The B2C model generally refers to business-to-consumer transactions. Currently, this model is used in online retail sales. The $\mathrm{C} 2 \mathrm{C}$ 
model is the consumer-to-consumer transactions, this model usually needs to rely on a third-party service platform to perform the business activities.The $\mathrm{C} 2 \mathrm{~B}$ model is a recent extension of an application-based model, which mainly refers to the transactions between consumers and manufacturers, the major feature is that consumers can customize the production of customized products. The $\mathrm{O} 2 \mathrm{O}$ model is an extension of online e-commerce activities, online fun, offline experience, which brings the distance between consumers and goods closer (free translation by ZHAO; FENG, 2017, p. 1).

Zhao and Feng (2017) define e-commerce as the use of the internet to engage in commercial activities. Thus, it can be said that e-commerce makes use of a variety of electronic tools for the management and operation of commercial activities of companies, for the management of sales to customers, whether people or organizations, since the authors identified the existence of different e-commerce models.

Since the internet appeared, one of the first possibilities glimpsed in the network was the opening of another sales channel for companies, in order to reach distant markets and not only those in geographically close regions. This was one of the first major impacts of the network, which triggered globalization and shortened the borders between people and companies, or even the business borders between companies in different countries and regions.

As time goes by and due to the increase in computing and communication technologies, software began to be developed for managing not only internet sales, but also for managing warehousing, logistics operations, and with the arrival of Industry 4.0, industrial management is also increasingly networked and interconnected to e-commerce platforms. The core of industry 4.0 is smart manufacturing, to realize communication between machines and equipment, materials, people, and objects (ZHAO; FENG, 2017). Smart machines can make decisions according to programmable situations, but also with machine learning, acquired during the production process and according to fault records, proposing improvements.

One example of this communication between intelligent machines is the strategic collaboration between the companies ABB and IBM, which have teamed up to develop industrial solutions using artificial intelligence for machine learning. The solutions from this partnership offer real-time cognitive knowledge services for smart factories and networks. With the union of $A B B$ Ability and IBM Watson Internet of Things cognitive capabilities the solutions are targeted at the industrial, transportation and infrastructure markets.

This group of innovative solutions aims to help organizations address some of their greatest challenges - improving quality control, reducing downtime, and increasing the speed and throughput of industrial processes - in a completely new way. The solutions enable connected systems, which currently only collect data, to become cognitive industrial machines. According to Ulrich Spiesshofer, CEO of ABB (apud IBM, 2017):

This strong collaboration truly marks the next level of industrial technology, moving beyond today's connected systems that simply collect data, to industrial operations and machines that use data to understand, analyze, optimize, and put in place actions that increase uptime, speed, and profitability for industrial customers.

Watson's artificial intelligence will help find defects through real-time production images captured through an ABB system and then analyzed using IBM Watson IoT for Manufacturing. Previously, these inspections were done manually, which was usually a slow and error-prone process. By bringing the power of Watson's real-time cognitive insights directly to the factory floor in combination with ABB's industrial automation technology, industries will be better equipped to increase the volume of their production lines while improving product accuracy and consistency. As parts flow through the manufacturing process, the solution will alert the manufacturer of critical flaws - not visible to the human eye in assembly quality. This enables rapid intervention by quality control specialists. Identifying defects more easily affects all products on the production line and helps improve the company's competitiveness, helping to avoid costly expenses and damage to its reputation (IBM, 2017).

In addition, the evolution of the internet itself with the increase of mobile networks and the use of devices such as smartphones and tablets has changed the way people research and buy their products, since such devices make it easier for purchases to be made at any time and from any location. Through online shopping applications like Wish, Geek or AliExpress, for example, Chinese companies sell their products to several countries, while in applications like Mercado Livre, Enjoei or eBay any user (including individuals) can register to sell (or buy) new or used products. Thus, companies that want to sell more must invest in ecommerce, as well as e-commerce facilitates the management of a company along the lines of Industry 4.0.

E-commerce also facilitates sales forecasting for companies that manufacture products, since production can be scheduled based on orders in the company's e-commerce portal. For Zhao and Feng (2017) with the implementation of Industry 4.0 , the $\mathrm{C} 2 \mathrm{~B}$ model will be the main form of ecommerce sales for industries, and consumers will be the drivers of all their businesses. For these authors:

Compared with traditional high-volume industrial production, the $\mathrm{C} 2 \mathrm{~B}$ model with customers as the core, can accept users' customized needs and then organize production and procurement. From the first production order, it is possible to significantly reduce production without sales guarantees, reduce inventory and marketing costs, as well as provide users with services closer to their needs (free translation by ZHAO; FENG, 2017, p. 3).

Therefore, the integration of Industry 4.0 technologies and tools with e-commerce ones, when applied together make production, logistics operations, and sales actions more efficient, and as a consequence, companies can become more profitable.

\subsection{Customer Relationship Management (CRM) for retail with Industry 4.0}

A further technological evolution that contributed to the growth and adoption of tools that enable greater knowledge 
about customers and the storage of data about customercompany transactions, culminated in systems called Customer Relationship Management (CRM).

The concept of CRM is also approached as a business strategy aimed at understanding and anticipating the needs of a company's current and potential customers, based on market research that supports CRM, with the aim of developing strategies capable of increasing both customer loyalty and sales in a sustainable way (Bretzke, 2000).

CRM is also the integration of sales automation functionalities, customer service (callcenter), marketing automation and management information tools, which can be integrated to BackOffice systems, still linked to customer service in credit, invoicing and delivery. CRM is more than a technological solution, for some authors it is considered a revolution in the marketing and sales model, because the customer is now perceived by all departments of a company in the same way and marketing should no longer be focused only on the product, but on the needs, expectations and desires of each consumer.

CRM systems combine the philosophy of relationship marketing with the facilities provided by ICT infrastructure. Relationship marketing emphasizes the importance of attracting and retaining customers, and seeks to encourage the building of long-term relationships that are satisfying for both the customer and the company. And technologies provide the resources to integrate the functions of different departments within companies, impacting management in terms of their processes and employee training (DEMO et al, 2015).

One of the main Technologies needed to program CRM is the database, which is the main point to store all the initial information in order to improve the customer relationship. Thus, customer information stored in a database can be accessed via the Internet or by the retail sales force's smartphone, for example. With the growth of data storage options with virtualization and big data processing, which are Industry 4.0 developments, and by applying such developments to CRM systems, retail companies have an expansion over their market prospecting capabilities and improvement over product offerings, logistics and promotions. Thus, companies can monitor in real time the Internet browsing of potential consumers and identify the demand for a particular product, they can even monitor data about the competition through tools such as data mining, and with the systems talking to each other, they can offer valuable information for a retail company's strategic decisions. Even competitive intelligence and digital marketing tools would come into play.

According to Demo et al (2015) CRM should be applied with a managerial approach to understand and impact customer behavior through the systematic study of transactions performed, based on information stored in computerized systems, which aims to increase purchases through retention, loyalty and profitability. These authors emphasize the need for integration between processes, operations, and people, with marketing being a philosophy that guides the entire business. It is a holistic view of relationship marketing, integrating all parts of the organization.

In CRM systems it is possible to obtain data about the customer's purchase history and propose new transactions based on his habits, even reminding him about the need to make new purchases, even before $\mathrm{He}$ needs or seeks a competitor. As all transactions are stored in the system, the relationship with the customer can be strengthened because the company knows his preferences and can offer benefits that are decisive for the purchase (Bretzke, 2000). There are different databases to obtain information about customers, both internal ones that are created from customer interactions with the company, as well as external ones that can be data collected from customers who visit the company's website, or who participate in cultural contests and other interactions with the company. It is also currently possible to capture data from social networks, and companies should choose the relevant information for their business and use it in the best possible way.

It is also possible to adapt elements of a CRM system for a certain type of industry or company, just as CRM processes exist using standardized tools. Some CRM vendors provide ready-made solutions for the automotive industry, retail, banking, or the pharmaceutical industry. A good example of using CRM is to get the most complete data possible to get to know your customers in order to make recommendations to them about product purchases or service contracting needs. From the organized customer data it is possible to discover trends and buying habits, classifying customers into groups based on similarities, and thus develop new products and services for specific audiences. The continuous learning about customer habits generates new business opportunities.

The technological development of Industry 4.0 provides an increasing number of tools that enable the company to develop a better understanding of the behavioral patterns of its customers, as well as to obtain information about their needs and inclinations. Having this information, it is the company's responsibility to employ these tools to customize marketing and sales offers for each type of customer.

\section{CONCLUSION}

As of the turn of the millennium, due to the various technological advances that occurred mainly in three areas digital, physical, and biological - the emergence of the fourth industrial revolution began to be evidenced, which is largely supported by these advances and by principles that guide the concept of Industry 4.0.

The basic principles of this revolution are interoperability, virtualization, decentralization, real-time operability, service orientation, and modularity.

Interoperability refers to the ability to communicate between humans and machines and between machines and machines in factories equipped with cyber-physical systems. Such systems provide real-time connection and communication between all involved in production, through the Internet of Things and the Internet of Services, which also connects such systems with the company's e-commerce. The interoperability between objects and humans, or objects and systems with the use of IoT brings great possibilities for improvements in retail planning and strategies, since both appliances and electronic devices installed in homes or offices will be able to communicate with the e-commerce of food or computer supply retail chains and inform when home stocks are low, and even place orders and purchases without the need for a human. As such, retail CRM when interfaced with smart electronics becomes an ally for production planning and control, or for marketing, sales, and logistics decisions. 
Virtualization means that cyber-physical systems are able to monitor physical processes, by means of sensors, which monitor physical processes and simulation models, improving the decision-making power in adverse situations.

Decentralization occurs due to the increasing consumer demand for customized products and makes it increasingly complex to control systems centrally. Thus, decentralization means the ability of cyber-physical systems to make decisions on their own in Industry 4.0 factories.

By the same token, the ability to collect and analyze data and deliver the information in real time helps the manufacturing plant, which can react quickly to a machine failure and redirect products to another machine. Or for the retail case this possibility helps to monitor issues of strategic interest, such as consumer buying habits and preferences, or to identify, locate, and track competitors or possible new entrants to the industry, since Industry 4.0 linked with industrial automation both use technology, focused on process optimization.

Service orientation is because due to the help of machines, humans will be more available to better service customers, as the internet of things will be connecting operations and some tasks will no longer need to be so people-driven.

Finally, modularity means that Industry 4.0 factories have become a reality, and can be flexibly adapted in terms of replacing or expanding individual modules. Modular systems can be easily adjusted in the event of seasonal fluctuations in demand or changes in product characteristics.

The great impact of Industry 4.0 as a new industrial revolution, marked by artificial intelligence, where it is possible to optimize and customize products and service; by connectivity between machines, which are capable of cooperation within industries and of adding great changes to operations; virtual reality; mobile devices; $3 \mathrm{D}$ printers; and many other tools capable of increasing production and integrating with technological capacity.

In nutshell, a large amount of data is generated from a variety of resources capturing online operations (e-commerce transactions, web browsing, social media interactions, etc.). These online interactions contain a large volume of data and the concept of big data, which means working this large flow of data with respect to its analysis, capture, search, sharing, storage, transfer, visualization, and data privacy information (SCHWAB, 2016).

\section{REFERENCES}

[1] ABB no Brasil. ABB lança o ABB Ability, seu portfólio de soluções digitais para indústria. 14/03/2017. Disponível em: <http://www.abb.com.br/cawp/seitp202/ 4e492a6df8440d94c12580e3006a7157.aspX.

[2] BRETZKE, Miriam. Marketing de relacionamento e competição em tempo real. São Paulo. Brasil: Atlas, 2000.

[3] DATOSMACRO.COM. BRICS 2018. Disponível em: <https://www.datosmacro. com/paises/grupos/brics>.

[4] DATTA, P. A preliminarystudyofecommerceadoption in developing countries. Information Systems Journal, v. 21, n. 1, p. 3-32, 2011.

[5] DEMO, Gisela; FOGAÇA, Natasha; PONTE, Valter; FERNANDES, Thais; CARDOSO, Humberto. Marketing de relacionamento (CRM): estado da arte, revisão bibliométrica da produção nacional de primeira linha, institucionalização da pesquisa no Brasil e agenda de pesquisa. RAM, Revista de Administração Mackenzie, São Paulo, v. 16, n. 5, p. 127-160, out. 2015. Disponível em: <http://dx.doi.org/ 10.1590/167869712015/administração.v16n5p127-160>.

[6] EBIT. Relatório Web shoppers. 36a . edição. 2017. Disponível em: 〈https://www.ebit.com.br/webshoppers〉.

[7] EMARKETER. Mobile IsDrivingRetailEcommerce Sales Worldwide. eMarketerRetail. January 29, 2018. Disponível em: <https://retail.emarketer.com/article/global-ecommercetopped-23-trillion-2017-emarketer-

estimates5a6f89f5ebd40008bc 791221>.

[8] FERREIRA, P. G. A oportunidade da Indústria 4.0 para o Brasil. Blog do IBRE, Instituto Brasileiro de Economia, Fundação Getúlio Vargas. 30/05/2017. Disponível em: $<$ http://blogdoibre.fgv.br/posts/ oportunidade-da-industria-40para-o-brasil>

[9] GILCHRIST, A. Industry 4.0: the industrial internet ofthings. California: Apress: 2016.

[10] HERMANN, M.; PENTEK, T.; OTTO, B. Design Principles for Industrie 4.0 Scenarios: a literature review. Working Paper No. 01/2015, Technische Universität Dortmund. Disponível em: <http://www.snom.mb.tudortmund.de/cms/de/forschung/ Arbeitsberichte/DesignPrinciples-for-Industrie-4_0-Scenarios.pdf >.

[11] IBM. ABB e IBM se unem para criar inteligência artificial industrial. Falando de TI. 3 maio 2017. Disponível em: <https://www.ibm.com/blogs/robertoa/2017/05/abb-e-ibmse-unem-para-criar-inteligencia-artificial-industrial/> .

[12] SCHWAB, K. A quarta revolução Industrial. São Paulo. Brasil: Edipro, 2016.

UZOKA, F. E.;SELEKA, G. G. B2C E-Commerce Development in Africa : Case Study of Botswana. Accounting and Finance, p. 290-295, 2006.

[13] WE ARE SOCIAL; HOOTSUITE. Digital in 2018: Global Overview. Essential insights into internet, social media, mobile and e-commerce use around the World. Special Reports from We Are Social and Hootsuite. Disponível em: $<$ https://wearesocial.com/blog/2018/01/global-digital-report2018>.

[14] WONG, X.;YEN, D. C.; FANG, X. E-commerce development in China and its implication for business. Asia Pacific Journal of Marketing and Logistics, v. 16, n. 3, p. 68-83, 2004.

[15] ZHAO, L.; FENG, M. Study on the Transformation and Upgrade of E-Commerce Application in Manufacturing Industry. MATEC Web of Conferences, n. 100, 02042, 2017. Disponível em: <https://www.matecconferences.org/articles/matecconf/abs/ 2017/14/mat ecconf_gcmm2017_02042/matecconf_gcmm2017_02042.html $>$. 